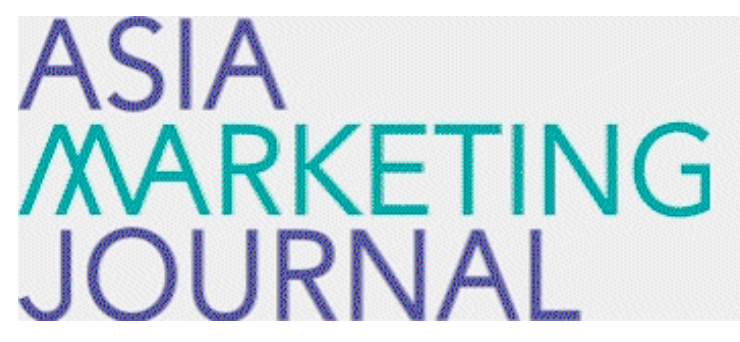

ASIA MARKETING JOURNAL

Volume 14 | Issue 3

Article 11

$10-30-2012$

\title{
Caffe Bene: Creating Values for Customers
}

Kwang Ho Ahn

Chang Jo Yoo

Young Chan Kim

Follow this and additional works at: https://amj.kma.re.kr/journal

Part of the Marketing Commons

\section{Recommended Citation}

Ahn, Kwang Ho; Yoo, Chang Jo; and Kim, Young Chan (2012) "Caffe Bene: Creating Values for Customers," Asia Marketing Journal: Vol. 14 : Iss. 3 , Article 11.

Available at: https://doi.org/10.53728/2765-6500.1496

This Article is brought to you for free and open access by Asia Marketing Journal. It has been accepted for inclusion in Asia Marketing Journal by an authorized editor of Asia Marketing Journal. 


\title{
Caffe Bene: Creating Values for Customers
}

\author{
Kwangho Ahn* \\ Changjo Yoo** \\ Youngchan $\mathrm{Kim}^{* * *}$
}

Caffe Bene, one of the most notable coffeehouse chain brands in Republic of Korea, gives us some thought-provoking issues in terms of sustainable success. Despite harsh competition among various coffeehouse brands, Caffe Bene has been accomplished astonishing outcomes in domestic market and now ranked $2^{\text {nd }}$ place in sales among the global coffeehouse franchise in 2010 and 2011. These achievements were possible mainly because Caffe Bene adopted distinctive shop design, maintained aggressive marketing strategy, developed new menu, and combined the unique Korean culture with ordinary concept of café to make its place attractive.

However, since Korean coffeehouse market is getting saturated and consumers are becoming savvy about coffee. Caffe Bene needs to find a new solution to overcome growth stagnation. Besides, many experts pointed out that irrational increase in the number of stores might hurt its business in the aspect of managing distribution channel and providing consistent services. Also, customers of Caffe Bene have shown that it has to complement its critical weaknesses: inferior coffee taste and relatively high price for a cup of coffee. Especially, some people view that the company is shifting its high rental fee, interior cost and PPL marketing cost to consumers by charging high price for coffee.

To get over the problems. Caffe Bene is currently using C/S Consumer Management System though experts are questioning about the efficacy because of the conflict between purpose of the system and the headquarters' plan. Present CEO Kim also announced that the company will complete its logistics system in the latter half of 2012 to provide stores with more high quality coffee beans to improve taste of coffee.

Thus, in this case. we describe how Caffe Bene succeeded in Korean market and enumerate its key success factors. Also, we specify the long-term goals of Caffe Bene and introduce the current policies and strategies to show how the company is working on to achieve its ultimate goal. By reading and analyzing this business case, students could get useful insights regarding franchise management and think about issues on competing in a saturated market. Also, it would be worthwhile to generate creative solutions for the problems that Caffe Bene is now facing to broaden the practical perspective.

Key words: coffeehouse, franchise, market saturation, customer value, long-term success

\footnotetext{
* Professor. Inha University(ahnkh@inha,ac,kr)

** Professor, Dongguk University(yoo@donggukedu)

*** Professor. Yonsei University (youngkim@yonsei.ac.kr)
} 
On February 17th, 2012, Sun-kwon Kim, the CEO of a Korean traditional coffeehouse chain brand 'Caffe Bene', had a meeting with the reporters in Caffe Bene New York branch, located on the first floor of Manhattan Crown Hotel New York. Getting the spotlight from many people, he announced the achievements that Caffe Bene has made so far and the business road map to grow as a global company.

Professor Allen H. Kupetz (Crummer Graduate School of Business at Rollins College) has a very positive view with this said at an interview with Financial News, "Korean coffee culture is unique. For home being place for whole family and working site is place for the living, coffeehouses have emerged as 'the third place' where they can free themselves from the stresses gained from home and job." He also expected that coffeehouse brands will continue to grow eventually in the future.

But on the other hand, the opinion of the former CEO Hoon Kang (present CEO of Brand Mango Six), who had played a big role for the success of Caffe Bene is a bit different. He believed that once Caffe Bene exceeds 500 stores in Korea, it would experience stagnation. Indeed, Caffe Bene had already exceeded 500 stores by February, 2011 and is suffering of over competition. Moreover, Mr. Kang pointed out that the order of priority is reversed. In other words. Caffe Bene has been concentrating too much on spreading the Korean cafe culture such as a new style of coffee such as a grain latte and the book cafe concept, instead of being focus more on coffee itself. Hoon Kang points out that Caffe Bene does not have competitiveness in the taste of coffee, which is the most important factor to become successful coffeehouse branch, and it might be the biggest obstacle in making a long term success.

Mr. Kang also criticizes the expansion strategy of Caffe Bene at a news conference, "To gain a sustainable success into the future. Caffe Bene has to insure its core capability, instead of focusing on expanding the number of branches." For instance, when Starbucks fell in crisis on 2007 due to its absorption on external growth, founder CEO Howard Schultz presented the improvement of coffee quality as the most important reform measure. On February 26, 2008, he closed around 7,100 stores in America to retrain its baristas on espresso sampling process. On the contrary. Caffe Bene has set to become global brand which would surpass the Starbucks, merely by using its marketing effort.

To overcome such circumstances Caffe Bene is facing, CEO Kim raised the following question on strategy meeting with heads of all departments: "How can we overcome the overflow and harsh competition in the Korean coffeehouse market? How can we deliver the best values to our customers? And what really are the values that are most important to our customers?" 


\section{The Company}

\subsection{Caffe Bene}

Caffe Bene was founded by the current CEO Sun-kwon Kim in 2008 at 29 years of age, based on the experiences of gaining success on opening number of franchise restaurants. Ever since opening its first store on May 2008. Caffe Bene has experienced an extremely rapid growth, exceeding 500 stores in February 2011 and recently reaching 790 stores nationally in June 2012. Caffe Bene is ranked first in growing rate against operating period" among the major coffeehouses in Korea, followed by another Korean coffeehouse franchise "Angel-In-us".
As a result of such success, Caffe Bene ranked $2^{\text {nd }}$ place in sales among the global coffeehouse franchise, recording total sales of 101 billion won and 168 billion won in 2010 and 2011 respectively (see exhibit 1,2 , and 3 ). This figure is the steepest increase compare to any other domestic coffeehouse franchises, and the figure is still growing (see exhibit 4). Especially in 2011. Caffe Bene became the coffeehouse franchise having the most branches, by recording average increase of 16 stores per month, overwhelmingly exceeding 2.5 stores of Starbucks and 3.6 stores of Angel-In-Us (see exhibit 5). This monumental short term success shows that Caffe Bene has an exceptional capability of expanding their business.

〈Exhibit 1) Earnings Trend of Caffe Bene (won in billions)

\begin{tabular}{|c|c|c|c|}
\hline & 2009 & 2010 & 2011 \\
\hline Sales & 224 & 1.023 & 1,680 \\
\hline Profits & 5 & 152 & 173 \\
\hline Net Income & 3 & 112 & 119 \\
\hline
\end{tabular}

Source: From Financial Supervisory Service. 2011

〈Exhibit 2〉 Sales of Korean Major Coffeehouses (won in billions)

\begin{tabular}{|c|c|c|c|c|}
\hline Ranking & Company & Sales & Profits & Net Income \\
\hline 1 & Starbucks & 2982 & 225 & 181 \\
\hline 2 & Caffe Bene & 1680 & 173 & 119 \\
\hline 3 & Coffee Bean & 1338 & 107 & 57 \\
\hline 4 & Tom and Toms & 625 & & \\
\hline 5 & Holly's & 577 & & \\
\hline 6 & Coffin Grunaru & 231 & & \\
\hline
\end{tabular}

Source: From Financial Supervisory Service, 2011 
〈Exhibit 3〉 Growth of Caffe Bene

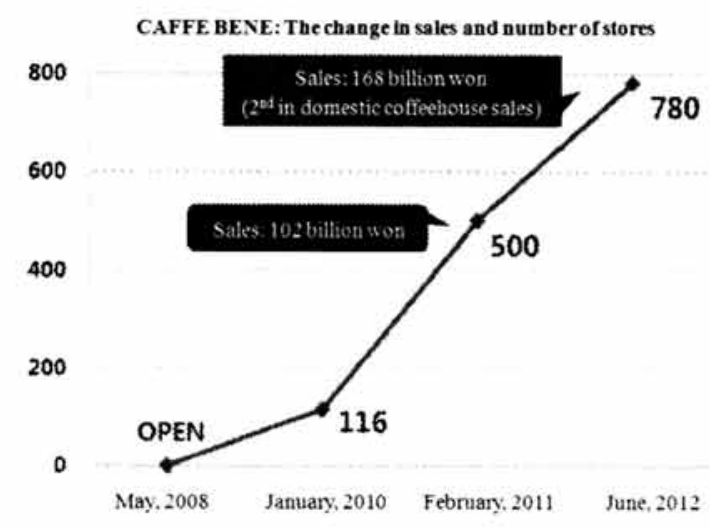

$\langle$ Exhibit 4〉 Number of Stores of the Major Coffeehouse Brands

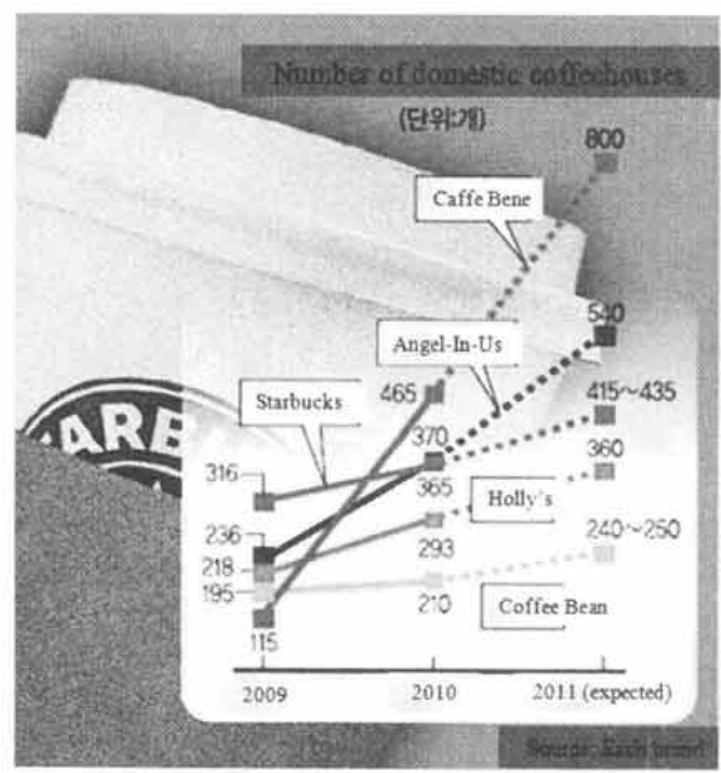

- 2,182 at year 2010, over 3200 at year 2011 .

- The number of stores is an annual accumulation.

\subsection{The Success Factors of Caffe Bene}

Since the Korean coffeehouse market had been dominated by mighty global brands, many domestic and foreign experts highly respect the

188 ASIA MARKETING JOURNAL Vol. 14 No. 03 October 2012 fact that Caffe Bene had overcome such adverse condition with aggressive marketing strategy especially as a local brand and latecomer.

Mr. Kim is always confident about the philosophy that led Caffe Bene to success: "Caffe Bene is based on the philosophy that coffee is not just ordinary beverage, but culture. With this in mind, we conceptualized the first European style coffeehouse in Korea. This is the main reason of success."

The specific factors which led to the rapid growth of Caffe Bene in Korean market are as follows:

- Specialized design and marketing: Caffe Bene is highly valued for unifying its stores' appearances, outdoor signs, and logos with an accorded and fresh design. While most foreign coffee brands focus primarily on take-out, Mr. Kim consistently pursues 'high-concept' stores where consumers can have comfortable relaxation, cultural experience. and fulfill their sensitivity. Wooden chairs and tables with rich texture, bookstands, and all those unique small items placed in Caffe Bene are to express such concept. Moreover, the harmonized outdoor appearance with these interiors and its cultural and colorful logos are made of the same concept. Such effort and distinctiveness has successfully drawn the positive reaction from consumers (see exhibit 6). 
〈Exhibit 5〉 Number of Stores of the Major 5 Coffeehouse Brands in Korea

\begin{tabular}{|c|c|c|c|c|c|c|}
\hline Brand & Type & 2007 & 2008 & 2009 & 2010 & 2011 \\
\hline Starbucks & Retail & 233 & 282 & 292 & 330 & 400 \\
\hline Coffee Bean & Retail & 111 & 148 & 188 & 195 & 217 \\
\hline Caffe Bene & Retail. Merchant & - & - & 170 & 420 & 735 \\
\hline Angel-In-Us & Retail. Merchant & 62 & 143 & 277 & 349 & 570 \\
\hline Holly's & Retail. Merchant & 130 & 183 & 230 & 287 & 336 \\
\hline Total & & 536 & 756 & 1,157 & 1,581 & 2.258 \\
\hline Growth (\%) & & 37.8 & 41,0 & 53.0 & 36.6 & 42.8 \\
\hline
\end{tabular}

Source: From Financial Supervisory Service, 2011

〈Exhibit 6〉 Satisfaction of Stores and Facilities of Caffe Bene

Store atmosphere/Facilities Differentiation

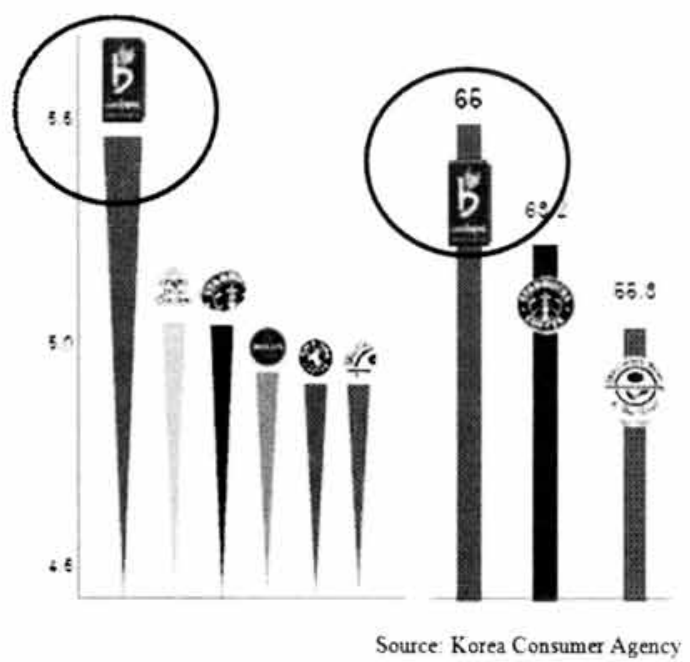

- Star marketing for popularity: Caffe Bene utilized many distinct factors actively for marketing purpose, and one of the most representative factors is the star marketing for a gaining popularity and activating cultural marketing. Caffe Bene made strategic alliance with the biggest entertainment company Sidus HQ in 2009, and started number of famous celebrities such as Ye-seul Han and Seung-hun Song in its TV commercial. At the same time, it draws the attention of people by using PPL marketing, exposing its stores in TV dramas and movies. Mr. Kim thinks that this kind of aggressive star marketing is the key success factor for gaining rapid popularity in Korea, where many people are influenced by TV program. Furthermore, Caffe Bene also informs consumers about its seasonal or new menus by using advertisements in magazine and newspaper, along with advertisements at bus and subway from time to time.

- Providing a cultural, valued, and resting complex place: Caffe Bene's goal was to create venue that is more than just drinking a cup of coffee or getting take-out, but also a complex cultural place where people can relax and enjoy their stay. To accomplish this, Caffe Bene created a free PC zone and put bookshelves with many books like a book cafe. Caffe Bene also receives 
about 70-80 music requests from consumers per day. Mr. Kim also emphasizes the importance of culture with many different means, such as hosting an event which patronizes many cultural art activities.

- The creation of representative products and R\&D menu development: Caffe Bene is known for its ability to seize the need for new or seasonal menu and developing it quickly for sale. Caffe Bene presents a diverse product line along with original single coffee by classifying its consumers, for example, to desert manias, a well-being group, and women of marked individuality, and etc. To satisfy all these various types of consumers, it creates various specialty menus for each segment. Some of the best examples are Belgium waffle, Italian gelato, and healthy beverages like 'grain latte'.

- Bene Cup Coffee College: Bene Cup Coffee College is the first Korean Coffee education academy which provides high education programs on various matters about coffee with high-tech facilities. The educational programs vary from training professional baristas and staffs to simply experiencing the coffee making process for ordinary consumers. The underlining purpose of these programs is Mr. Kim's intention to increase the general public's interest on coffee. The College provides also an organized system for general consumers to become professional baristas through a "one-stop processes.'

\section{The Market}

\subsection{Coffee Industry in Korea}

Korean coffee industry, which is comprised of instant coffee, can coffee, and coffeehouse markets, has been experiencing rapid growth since 2007 to especially 2011. The instant coffee market possess highest market share within the industry, followed by coffeehouse and can coffee market (see exhibit 7). A meaningful trend is that whereas the market share of the instant coffee was predominated in 2009, the coffeehouse market has grown rapidly since 2011 and showing similar market share with instant coffee market.

〈Exhibit 7〉 Composition and Trend of the Korean Coffee Market

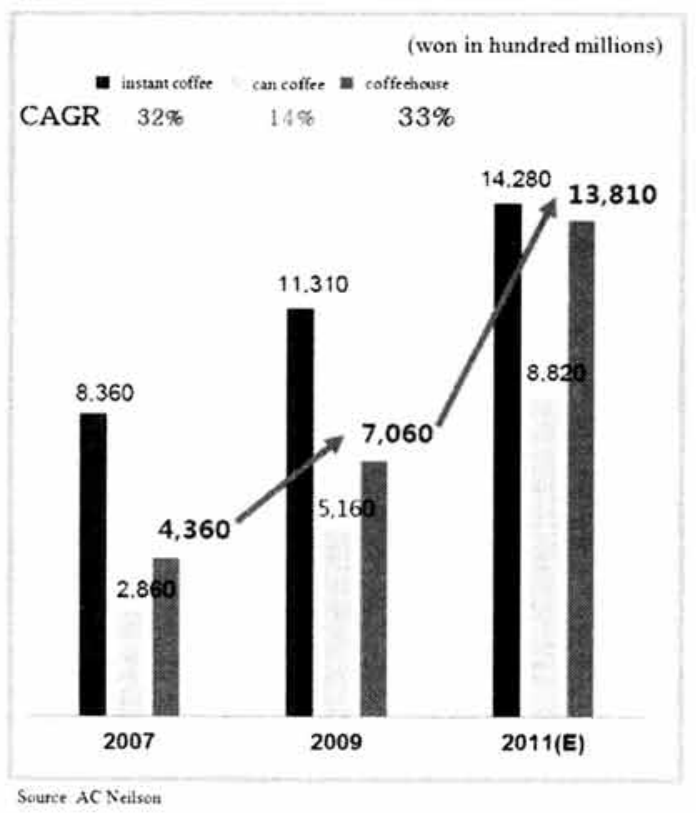


2.2 Current Situations of the Coffeehouse Market in Korea

\subsubsection{Market Growth}

The domestic coffeehouse market has been growing since 2006. According to 〈The Report of the National Coffeehouse Market Movement〉 published by KB Financial Holding Business Research Institute, the number of coffeehouses has increased from 1,254 in 2006 to 12,381 in 2011 (see exhibit 8). Moreover, according to Financial Supervisory Service, the sales profits of six major coffeehouses in Korea (Starbucks, Caffe Bene, Coffee Bean. Tom and Toms. Holly's, and Coffin Grunaru) increased 28.0\% compared to the past year from 580.7 billion won to 743.3 billion won. Comparing to the Korea GDP growth rate $3.6 \%$ in 2011, the six coffeehouses have a growth rate almost eight times higher. Including other coffee brands such as Angel-In-Us and Twosome Place which also have a high popularity in Korea, the growth rate of the coffeehouse market is expected to be much higher than these figures.

The popularity of coffee did not decrease even during the economic recession in 2009 and 2010. and rather spread to close-to-life places such as residential quarter areas, bookstores, and large marketplaces. Now, various sizes and brands of coffeehouses are in almost every place, and some business districts have more than ten coffeehouses within few blocks (see exhibit 9).

〈Exhibit 8> Number of Store Growth by Major Coffeehouse Brands in the Last Three Years Increase of domestic coffeehouses in the recent three-years

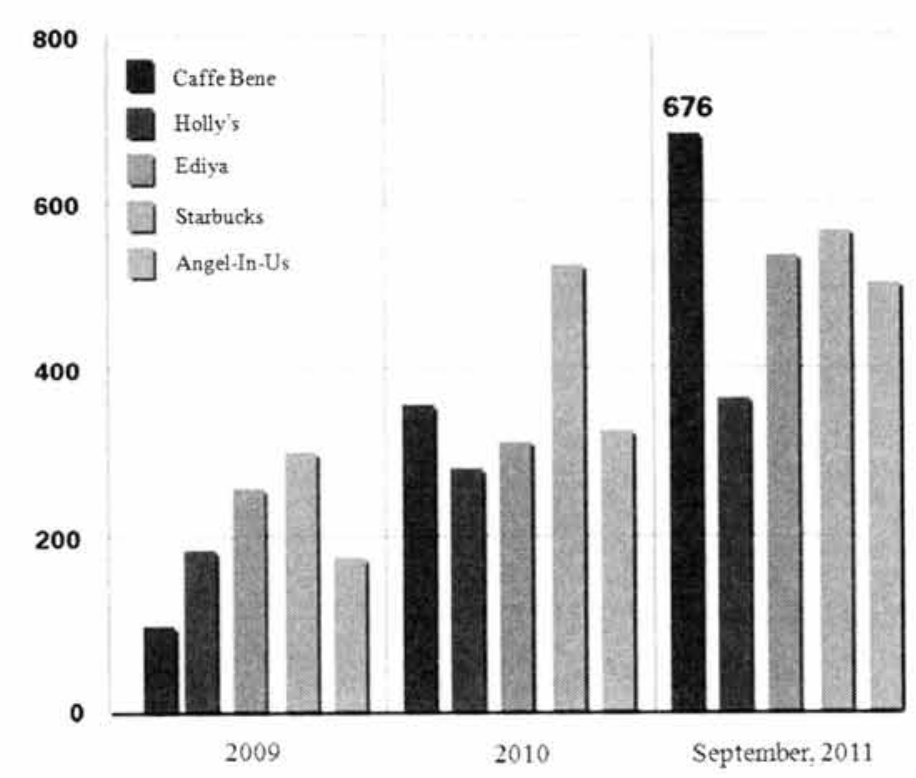


〈Exhibit 9〉 Map of Gangnam Area in Seoul(Korea) with Distribution of the Major Coffeehouse Brands

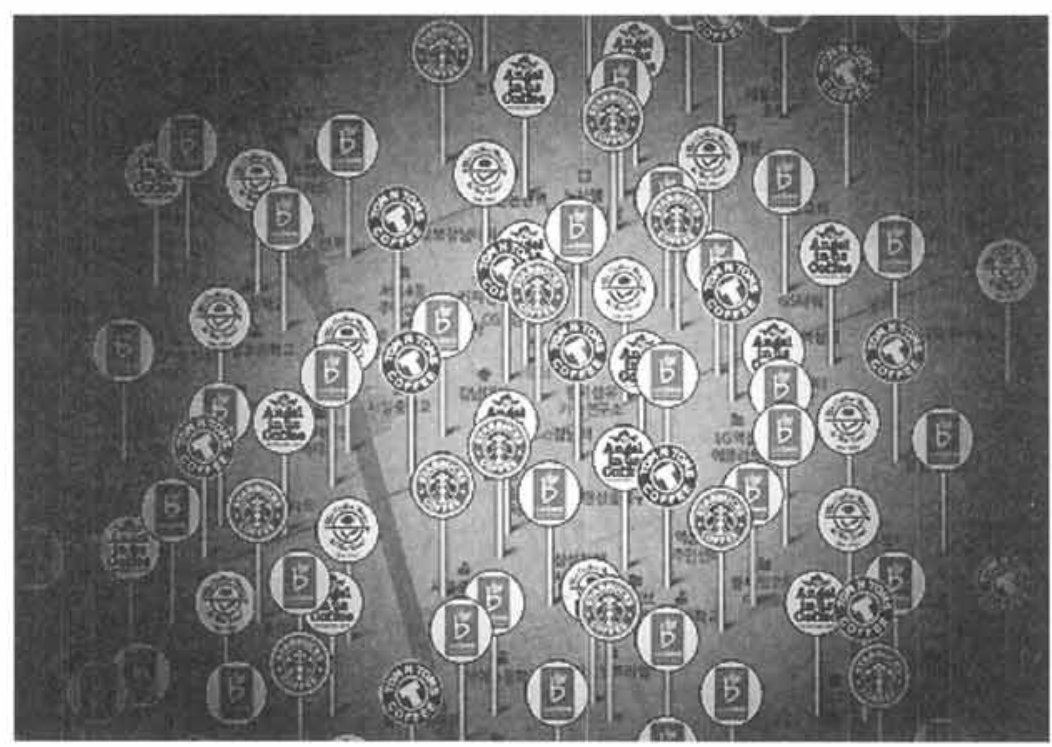

\subsubsection{Consumers}

Coffeehouses have drastically grown and made profits constantly in Korea coinciding with consumers change of perception and taste on coffee. The status of women in their twenties and thirties who are the main consumers of coffeehouses has also risen higher in Korean society. Furthermore, a culture of enjoying a tasty coffee in a comfortable and cozy place has also spread rapidly to men and the elders.

An article "What Consumers Want" published in 2010 by The Korea Economic Daily shows the supporting data that 'the era of coffee' has been one of the new lifestyle trends in Korea. According to the results of the research, consumers who visit a coffeehouse alone took up $14.0 \%$, and consumers who visit a coffeehouse with their friends, co-workers, or lover were up to $80.0 \%$. Most of the consumers thought that the price of coffee was way too expensive $(86.0 \%)$ nonetheless they go to a coffeehouse to make a social relationship. In fact, even new coined words arose for consumer groups who use coffeehouse as a particular space: a 'cafe-brarian group' who studies in a cafe just like in a library, a 'academy mom' group who shares and exchange information about their children and education with other parents in a cafe, and a 'coffice group' who have business meetings or have conferences in a cafe. The popularization of digital devices such as laptops, tablet PCs, and smart phones also makes consumers stay by themselves in a cafe more naturally. To satisfy these segmented consumer groups, coffeehouses are putting great efforts such as opening 24 hours, installing conference rooms, and providing free wireless internet, etc. 


\subsection{Changes in the Market}

\subsubsection{Over Competition}

In 2012, the future of the domestic market for coffeehouses does not seem bright. Coffeehouses are in everywhere which is causing market saturation and it looks axiom that it is now time to find a new solution to survive in this overheated market. According to the statistics, many of the coffeehouses are in danger of going out of business while their numbers are still increasing. A recent article in Kukmin Ilbo in June 2012 states that Caffe Bene which has the most market share during January to May 2012 opened 51 stores but closed 50 stores at the same time in nation wise. Starbucks, which is third place in market share, opened 50 stores but also closed 35 of them.

This phenomenon exactly corresponds to the concerns of experts who predict that the growth rate of the coffeehouse market will gradually slow down soon. And since the local competition is fierce and the franchisees are not able to afford its high rents, many store-owners are looking for the sites in rural area rather than in Seoul or metropolitan area. But now, even this is getting harder, because most of the major coffeehouse brands already have many stores throughout the country. For example, Caffe Bene has 548 stores in places other than Seoul out of its 814 stores in Korea (August, 2012). meaning that Caffe Bene is at almost anywhere in Korea. Won-gap Park, the chief real-estate manager of Kookmin Bank, said "Most of the coffeehouses are located on the first floor of a building with a high rental cost which causes big financial problems that franchisees have to endure. Also, the saturated market condition is negatively affecting the stores' profitability. If there is no way to expand the market, restructuring should be done in the near future."

In fact, a similar issue has been raised in early 2011. Hoon Kang, the former CEO of Caffe Bene and current CEO of Mango Six, said he already knew that irrational increase in the number of the stores can lead to failure in managing distribution channel and providing consistent services. An article in the Money Today in September 2011 pointed out the problem regarding reliability of the revenue due to harsh competition among franchises. This is still a serious issue for Caffe Bene, since it has 815 stores in Korea, which is a relatively big number comparing to Strabucks (which has 505 stores in Korea), but has only $55 \%$ of the revenue. Starbucks constantly is trying to make an inroad into Korean market: whereas Caffe Bene keeps on opening new franchise stores, called a multi-store strategy. The biggest problem of the strategy is that Caffe Bene has too many franchise stores - about $97 \%$, rather than managing company-operated stores. Since there are over 800 Caffe Bene franchise stores throughout the country, the quality of taste and service has various problems the headquarter 
cannot control directly and efficiently.

As specialty-coffeehouse market gets saturated and more and more stores are threatened by excessive competition, Caffe Bene is now using the C/S Consumer Management System. This system is based on the mention of Sun-kwon Kim: "We are going to concentrate our abilities to go with our franchises." Nonetheless, a thorough market evaluation and the highlight on the virtue of co-exist between headquarter and franchises of this system created a conflict. This is because the headquarter already had a plan to enhance the stores that are companyoperated but made the experts skeptic about the efficacy of the system. Caffe Bene is now trying to figure out the creative and various solutions to overcome the problems about relationship between headquarter and franchises, profit share, self-cannibalization and reducing competition among franchises in saturated market condition. Through this, Caffe Bene will step up to creating customer value in the market by satisfying franchisees, consumers, and the market.

\subsubsection{Quality and Price Issues}

Even though domestic consumers regard great interior design and diverse menu as strong points of the Caffe Bene, they also bring up weak services and below average taste of coffee as a weak point. Although the fundamental principle of Caffe Bene is to provide consumers with the best quality coffee, they have only started to focus on the quality of the coffee after 2010. For Caffe Bene, it seems that the system to offer the best quality coffee is not their priority compare to other coffeehouse brands. Hoon Kang had mentioned about this problem in 2010 and regardless of its rapid growth rate it still has not changed yet. Sang-eun Lee, the CEO of coffee specialty company CKCO\&, said: "Headquarters of the coffee franchises must concentrate on profitability improvement rather than increasing the number of stores." In this context, it is understandable that the Caffe Bene has been criticized of its lack of effort to achieve sustainable profitability from the taste of coffee. Recently, it has been revealed that consumers are more knowledgeable about the quality and the taste of coffee and the coffee consumption has been increased. Moreover, nowadays, the opportunities to experience coffee bean roasting and blending coffee are increased and it shows that consumers actively exchange information through various communication channels. Price is another problem of Caffe Bene. According to the recent research about manufacturing cost of many specialty-coffee brands (see exhibit 10), the price of the Caffe Bene seems expensive relative to other coffee brands. In fact, even though the manufacturing cost of a cup of Americano is 123 Korean Won, Caffe Bene sells it for 3,800 Korean won which is the second most expensive price among the listed specialty-coffee brands. Since Caffe Bene stresses its indigenousness in their marketing and 
〈Exhibit 10〉 Price of Coffee by Korean Major Coffeehouse Brands

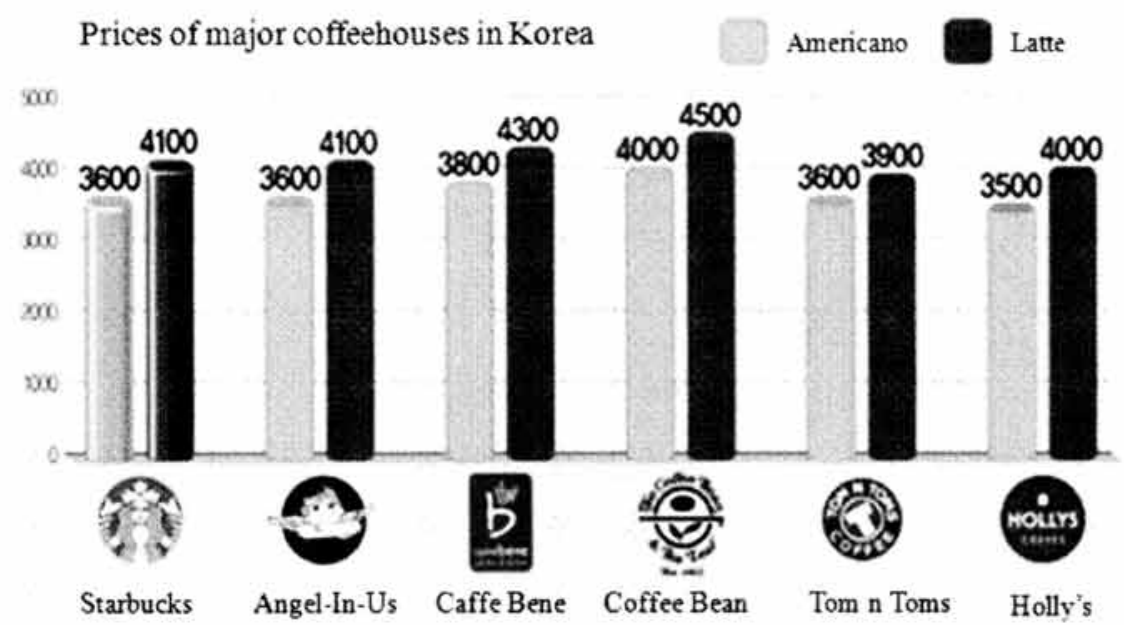

pays no loyalty to foreign company, high price of its coffee does not seem reasonable to consumers. Also, there are some who views that Caffe Bene is shifting its high rental fee, interior cost and PPL marketing cost to consumers by charging high price for coffee. In reality, it is true that the Caffe Bene is spending large amount of money on advertisement compared to competitors. It spent about 15 billion Korean won last year which increased by $64.6 \%$ com- $^{-}$ pared to 2010 in order to maintain aggressive advertisement strategy.

\section{Lessons from the Market}

Since 2008, Caffe Bene has been growing rapidly in the market with enormous power. In June 2012 Caffe Bene had about 790 stores and in August 2012 it had about 815 stores, and its ultimate goal is to have 1000 stores until the end of this year. Caffe Bene chose franchising to operate its business and its bold investment caused great number of the store, which made a big accomplishment in the market. But on the other hand, there are some problems arousing in the market that Caffe Bene has to deal with in order to gain sustainable success in the domestic market. The most important problem is that the coffeehouse market is overheated, which leads to high competition among brands, and even bring competition between Caffe Bene stores. The quality of taste and service is also a problem and is caused by the multi-store strategy, which the headquarter tries to increase the number of franchise stores to gain the market share advantage.

CEO Sun-kwon Kim is now trying to solve and avoid these troubles with franchises and to 
evaluate the situation of the market objectively. "Qualitative improvement strategy such as managing stores closely and increasing companyoperated stores will make it possible to sustain the growth." What he said in a meeting with issues on sustainable growth of Caffe Bene shows his strong determination and responsibility as a leader. Mr. Kim will have to solve the conflict between franchise stores and the companyoperated direct stores, since many franchisees are having problems in managing their stores and are angry to the Caffe Bene headquarters for focusing just on increasing to number of stores.

On the other hand, a wide variation in the taste of coffee among stores is also one of the most serious problems of the Caffe Bene and it is known as a critical shortcoming since it lessens the consumers' trust. To solve this problem, Caffe Bene tries to train their employees as professional barista and increase companyowned stores for the long-term success. Mr. Kim thinks this is a way Caffe Bene shows responsibility to the stores, managers, and consumers, and therefore all achieve a long term success.

Mr. Kim also announced that the company will complete its logistics system in the latter half of 2012 to provide stores with more high quality coffee beans to improve the taste of coffee. However, some experts say that it is desirable to back up fundamental competitive edge but the company needs to consider how much and how to invest new brand and logi- stics system after the growth period.

\section{Looking Ahead}

"My goal is to provide high quality services like the airline industry for consumers to impress them." As Sun-kwon Kim says, Caffe Bene needs to adapt its strategy based on real consumer needs and wants, and also the changing market situation for consistent growth. Specifically, Caffe Bene must firstly solve the problem of overcrowded franchise stores and the conflicts arising from it. And secondly, Caffe Bene must complement the quality and taste of the coffee. After all, it is certain that the Caffe Bene can make a second leap for the continuous growth based on its first leap.

\section{References}

Caffe Bene homepage (www.caffebene.co.kr)

Caffe Bene business introduction book 〈Investor Relations 2012>

'Revenue Stability Concerns of Cafee Bene and Angel-In-Us,'Money Today, 2011.9.7

'Coffeehouses 'A Trap of Excessive Competition'50 Open and 35 Close,' Kookmin Ilbo, 2012.6.18

'Coffeehouses Covering the Streets.' Sisa- In, 
2011. 2. 21

'Does the Coffeehouse Invincible Myth Crumple, E-Daily, 2012. 6.18

Sun-kwon Kim Caffe Bene CEO: Propagating our Sarang-bang Culture into New York and Throughout the World, Consumer Economy, 2012. 2.1
'What Do Consumers Really Want,' 2010, The Korea Economic Daily

Yoo et. al. (2011), The Power of Marketing and Advertising in Coffee Markets: A Case Study on Caffe Bene, Korean Journal of Advertising, 22 (2), 177-191. 